\section{Access to unusual polycyclic spiro-enones from 2,2'-bis(allyloxy)-1,1'-binaphthyls using Grubbs' catalysts: an unprecedented one-pot RCM/Claisen sequence $\dagger$}

\author{
Estefanía Piedra, Javier Francos, Noel Nebra, Francisco J. Suárez, Josefina Díez and \\ Victorio Cadierno*
}

Received 4th April 2011, Accepted 24th May 2011

DOI: $10.1039 / \mathrm{clcc11907a}$

Treatment of 2,2'-bis(allyloxy)-1, $\mathbf{1}^{\prime}$-binaphthyls with the firstgeneration Grubbs' carbene under MW-irradiation results in the formation of new polycyclic spiro-enones through an unprecedented RCM/Claisen sequence.

Olefin metathesis is one of the most useful chemical transformations for forming carbon-carbon bonds. ${ }^{1}$ In this sense, the rapid espousal of the ring-closing metathesis (RCM) of diolefins by synthetic organic chemists is remarkable, representing nowadays a highly efficient method of common use in laboratories for the synthesis of carbocyclic, heterocyclic, macrocyclic and fused ring frameworks. ${ }^{2}$ The broad utility of RCM reactions is largely due to the exquisite selectivity, remarkable efficiency and high functional group tolerance of ruthenium-based Grubbs-type carbene catalysts. ${ }^{3}$

On the other hand, 1,1'-binaphthyl compounds represent a relevant class of biaryl molecules whose participation in RCM processes has been scarcely investigated. Indeed, to the best of our knowledge, the 1,1'-binaphthyl scaffold has only been used in the construction of some helicene derivatives, ${ }^{4}$ cyclic peptoids with anti-bacterial activity ${ }^{5}$ and macrolactams, ${ }^{6}$ via RCM reactions. Herein, we contribute our bit to this field disclosing an efficient transformation of 2,2'-bis(allyloxy)-1,1'binaphthyls into unusual polycyclic spiro-enones, which is triggered by Grubbs' catalysts and involves an unprecedented one-pot RCM/Claisen rearrangement sequence.

Thus, initially we found that treatment of racemic 2,2'-bis(allyloxy)-1,1'-binaphthyl (1a) with $3 \mathrm{~mol} \%$ of the Grubbs first generation catalyst $\left[\mathrm{RuCl}_{2}(=\mathrm{CHPh})\left(\mathrm{PCy}_{3}\right)_{2}\right]$, in dichloromethane (1 M solution in substrate 1a) at $120{ }^{\circ} \mathrm{C}$ under microwave irradiation $(300 \mathrm{~W})$, results in the major formation of two new compounds after 3 hours, i.e. 2a and 3a in Scheme 1. NMR analysis of the crude reaction mixture revealed the total

Departamento de Química Orgánica e Inorgánica, IUQOEM, University of Oviedo, E-33006 Oviedo, Spain.E-mail: vcm@uniovi.es; Fax: + 34 985103446; Tel: + 34985103453

$\dagger$ Electronic supplementary information (ESI) available: Experimental section, characterization data and copies of the NMR spectra of all compounds, and theoretical calculations. CCDC 818286 (2a) and 818287 (3a). For ESI and crystallographic data in CIF or other electronic format see DOI: $10.1039 / \mathrm{clcc} 11907 \mathrm{a}$

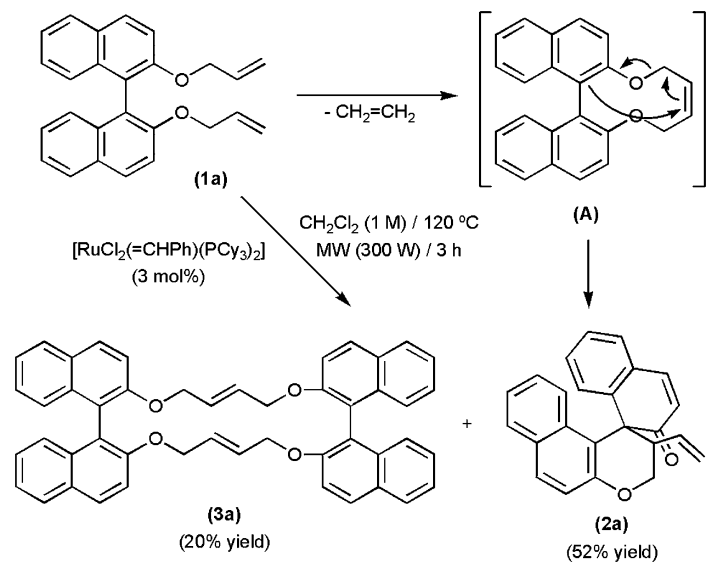

Scheme 1 Reactivity of 1 a towards $\left[\mathrm{RuCl}_{2}(=\mathrm{CHPh})\left(\mathrm{PCy}_{3}\right)_{2}\right]$.

consumption of the starting material 1a as well as the formation of minor amounts of other uncharacterized products, resulting probably from the competitive oligomerization of $\mathbf{1 a}{ }^{7}$ Chromatographic work-up over silica gel allowed the separation of $\mathbf{2 a}$ and 3a, which were isolated in pure form in 52 and $20 \%$ yield, respectively, and fully characterized by means of HRMS, IR and NMR spectroscopy (see ESI $\dagger$ ).

To our surprise, despite that the high-resolution mass spectrum of the major product $\mathbf{2 a}$ displayed the expected molecular ion peak $\left(\mathrm{M}^{+}+\mathrm{H}\right)$ for the intramolecular $\mathrm{RCM}$ product $\mathbf{A}\left(m / e\right.$ 339.1386), its ${ }^{1} \mathrm{H}$ and ${ }^{13} \mathrm{C}\left\{{ }^{1} \mathrm{H}\right\}$ NMR spectra were inconsistent with this formulation. In this sense, the appearance of a quaternary carbon at $56.9 \mathrm{ppm}$ and a $\mathrm{CH}_{2}$ signal at $115.7 \mathrm{ppm}$, typical of a terminal olefinic $=\mathrm{CH}_{2}$ unit, in the ${ }^{13} \mathrm{C}\left\{{ }^{1} \mathrm{H}\right\}$ NMR spectrum was particularly intriguing (confirmed by DEPT experiments). Consequently, to establish unambiguously the structure of this derivative a single-crystal X-ray diffraction study was undertaken (Fig. 1) $\dagger$

The structure revealed the formation of a spirocyclic compound by dearomatization of one of the naphthyl units, which is transformed into a cyclic enone via cleavage of one of the initial $\mathrm{O}-\mathrm{C}$ bonds. The observed C24-O2 (1.220(3) $\AA$ ), C23-C24 (1.458(4) A) and C22-C23 (1.332(4) A) bond lengths are in complete accord with the presence of a cyclic enone framework, 


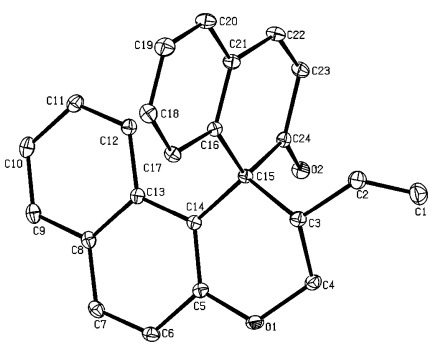

Fig. 1 ORTEP view of the structure of 2a. Hydrogen atoms have been omitted for clarity. Selected bond distances $(\AA)$ and angles $\left(^{\circ}\right)$ : C1-C2 1.287(5), C2-C3 1.494(4), C3-C4 1.506(4), C4-O1 1.430(4), C3-C15 1.585(4), C15-C24 1.542(3), C24-O2 1.220(3), C23-C24 1.458(4), C22-C23 1.332(4), C3-C15-C14 108.8(2), C3-C15-C16 105.5(2), C3-C15-C24 106.7(2), C14-C15-C16 112.3(2), C14-C15-C24 109.6(2), C16-C15-C24 113.6(2).

while the $\mathrm{C} 1-\mathrm{C} 2$ distance (1.287(5) $\AA$ ) shows a typical value for a non-conjugated $\mathrm{C}=\mathrm{C}$ bond. Re-examination of the ${ }^{1} \mathrm{H}$ and ${ }^{13} \mathrm{C}\left\{{ }^{1} \mathrm{H}\right\}$ NMR data confirmed their complete coherence with this unusual structure, which can be explained as the result of a Claisen-type rearrangement of the expected RCM product $\mathbf{A}{ }^{8}$ Such a reaction outcome is probably motivated by the ring strain within $\mathbf{A}$, associated with the twisted conformation that the $1,1^{\prime}$-binaphthyl-2,2'-diyl unit is forced to adopt. ${ }^{9}$ At this point, it is important to note that, although the combination of Claisen rearrangements with subsequent RCM reactions has been extensively studied during the last few years, allowing the access to a wide variety of carbocycles and heterocycles, ${ }^{10}$ including spirocyclic compounds, ${ }^{10 e-g}$ the reverse RCM/Claisen sequence has not been quoted previously in the literature. On the other hand, we must also note that, as shown by NMR, this unprecedented reaction proceeds in a diastereoselective manner (two stereogenic carbons are generated at $\mathrm{C} 3$ and $\mathrm{C} 15$ displaying $S S$ or $R R$ configurations; the latter is shown in Fig. 1). The twisted conformation of the binaphthyl unit in intermediate $\mathbf{A}$, along with the concerted nature of the Claisen rearrangement, can again be evoked to explain this stereochemical outcome (Fig. S3, see ESI $\dagger$ ).

Concerning the minor product, i.e. the 20-membered macrocycle 3a formed by metathetical dimerization of $\mathbf{1 a}$, its ${ }^{1} \mathrm{H}$ and ${ }^{13} \mathrm{C}\left\{{ }^{1} \mathrm{H}\right\}$ NMR spectra showed the complete equivalence of the four naphthyl units present in the molecule, as well as unique multiplet and singlet signals for the methylenic and olefinic protons, respectively, of the two $-\mathrm{OCH}_{2} \mathrm{CH}=\mathrm{CHCH}_{2} \mathrm{O}-$ linkers. This fact avoided the accurate assignment of the $\mathrm{C}=\mathrm{C}$ bonds stereochemistry which, thankfully, could be unambiguously determined as the $(E, E)$ one by means of a single-crystal X-ray diffraction analysis (Fig. 2). $\dagger$ Two very similar crystallographically independent molecules, differing only in the conformation adopted by the $-\mathrm{OCH}_{2} \mathrm{CH}=\mathrm{CHCH}_{2} \mathrm{O}$ - chains, were found in the asymmetric unit (only one is shown in Fig. 2).

The bond distances C22-C23 (1.319(7) $\AA$ ) and C46-C47 (1.328(4) $\AA$ ) showed the expected values for $\mathrm{C}=\mathrm{C}$ bonds, while those observed for C21-C22 (1.479(7) $\AA$ ), C23-C24

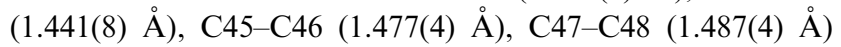
fall within the expected range for $\mathrm{C}\left(\mathrm{sp}^{2}\right)-\mathrm{C}\left(\mathrm{sp}^{3}\right)$ single bonds. These data, along with those obtained in solution by NMR, completely rule out the occurrence of $\mathrm{C}=\mathrm{C}$ isomerization

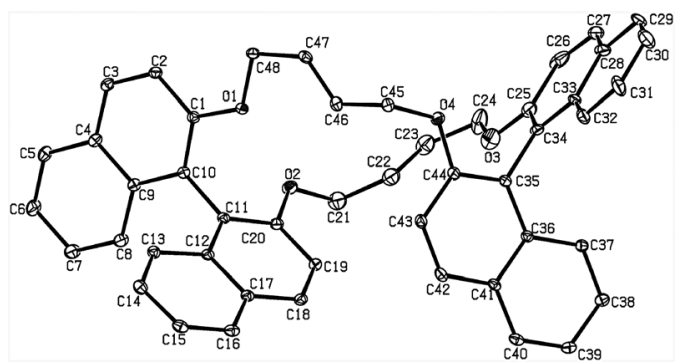

Fig. 2 ORTEP view of the structure of 3a. Hydrogen atoms have been omitted for clarity. Selected bond distances $(\AA)$ and angles $\left({ }^{\circ}\right)$ : O2-C21 1.426(5), C21-C22 1.479(7), C22-C23 1.319(7), C23-C24 1.441(8), C24-O3 1.393(6), O4-C45 1.437(4), C45-C46 1.477(4), C46-C47 1.328(4), C47-C48 1.487(4), C48-O1 1.419(3), C20-O2-C21 119.3(3), O2-C21-C22 111.5(4), C21-C22-C23 124.1(5), C22-C23-C24 128.1(5), C23-C24-O3 107.8(4), C24-O3-C25 119.0(4).
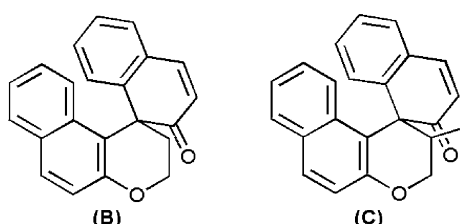

Fig. 3 Structures of the previously described spiro-enones $\mathbf{B}$ and $\mathbf{C}$.

processes, an undesired side reaction usually observed in olefin metathesis. ${ }^{11}$ No elements of symmetry within the molecule are present in the solid state, thus suggesting that the equivalence of the NMR signals observed in solution is due to conformational equilibria. ${ }^{12}$ Interestingly, $\mathbf{3 a}$ is generated in a diastereoselective manner by self-dimerization of the $R$ and $S$ enantiomers of $1 \mathrm{a}$ (the $R R$ enantiomer of the $R R / S S$ mixture is shown in Fig. 2), which is indicative of chiral recognition during macrocycle formation. ${ }^{13}$

The occurrence of spiro-enone $\mathbf{2 a}$ as the major reaction product is relevant given that, so far, only two previous examples of related polycycles (B and $\mathbf{C}$ in Fig. 3) have been reported in the literature. ${ }^{14}$

This fact prompted us to optimize our protocol with the aim to generate 2a in a more selective manner. To this end, we firstly checked the performance of the 2nd generation Grubbs catalyst $\left[\mathrm{RuCl}_{2}(=\mathrm{CHPh})\left(\mathrm{PCy}_{3}\right)\left(\mathrm{IMesH}_{2}\right)\right]\left(\mathrm{IMesH}_{2}=1,3\right.$-bis(2,4,6-trimethylphenyl)-4,5-dihydroimidazolin-2-ylidene), as well as that of the Hoveyda-Grubbs 1st generation carbene $\left[\mathrm{RuCl}_{2}\left(=\mathrm{CH}-2-{ }^{i} \mathrm{PrO}-\mathrm{C}_{6} \mathrm{H}_{4}\right)\left(\mathrm{PCy}_{3}\right)\right]$, under identical reaction conditions. However, none of them allowed us to improve the selectivity of the process. In both cases the macrocyclic compound 3a and higher oligomers were also formed, the yield of spiro-enone 2a being similar to that obtained with $\left[\mathrm{RuCl}_{2}(=\mathrm{CHPh})\left(\mathrm{PCy}_{3}\right)_{2}\right](50-55 \%)$. Variation of the solvent (THF or 1,2-dichloroethane), MW power and reaction temperature $\left(60-160{ }^{\circ} \mathrm{C}\right)$, under $\mathrm{MW}$-irradiation or classical thermal conditions, neither improved the selectivity, having in some cases a marked detrimental effect on the reaction outcome (lower yields of 2a or incomplete transformations). ${ }^{15}$ Fortunately, positive results were obtained by performing the catalytic reactions under more dilute conditions. In particular, using a $0.05 \mathrm{M}$ solution of $\mathbf{1 a}$ in dichloromethane and $3 \mathrm{~mol} \%$ of $\left[\mathrm{RuCl}_{2}(=\mathrm{CHPh})\left(\mathrm{PCy}_{3}\right)_{2}\right]$, the spiro-enone 2a could be 


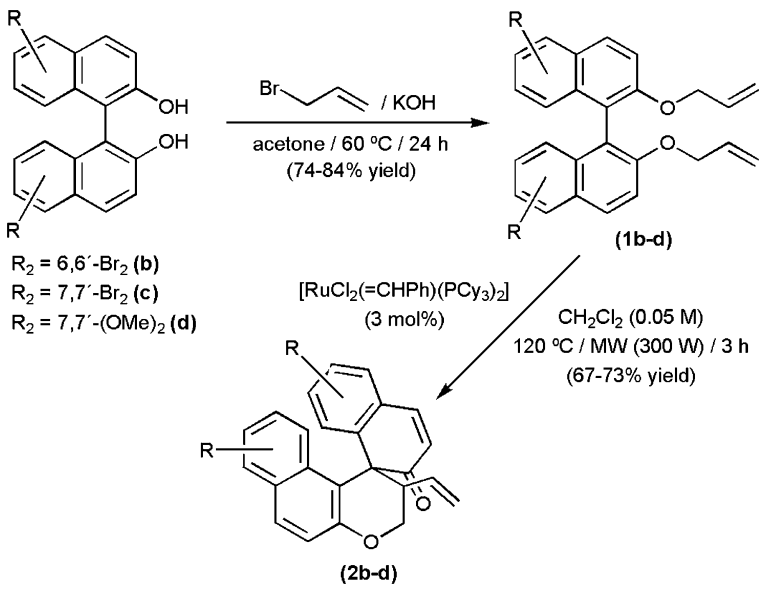

Scheme 2 Synthesis of spiro-enones $\mathbf{2 b - d}$.

obtained in a remarkable $79 \%$ isolated yield after $3 \mathrm{~h}$ of $\mathrm{MW}$ irradiation $(300 \mathrm{~W})$ at $120{ }^{\circ} \mathrm{C}$. Under these optimal conditions only $8 \%$ of dimer $3 \mathbf{a}$ was formed, the quantity of higher oligomers present in the crude reaction mixture being also despicable.

To further define the scope of this unusual carbocyclization process, the new 2,2'-bis(allyloxy)-1,1'-binaphthyls $\mathbf{1 b}$-d were synthesized from the corresponding symmetrically disubstituted 2,2'-dihydroxy-1,1'-binaphthyls and subjected to the optimized reaction conditions described above (Scheme 2). In all cases, complete consumption of the starting material was observed after $3 \mathrm{~h}$ of $\mathrm{MW}$-irradiation in the presence of $3 \mathrm{~mol} \%$ of $\left[\mathrm{RuCl}_{2}(=\mathrm{CHPh})\left(\mathrm{PCy}_{3}\right)_{2}\right]$. Analysis of the crude reaction mixtures by NMR showed the formation of the desired spiro-enones $\mathbf{2 b}-\mathbf{d}$ as the major reaction products (67-73\% isolated yield), thus confirming the generality of this new catalytic transformation (details are given in the $\mathrm{ESI} \dagger$ ). ${ }^{16}$

In summary, a straightforward and high-yielding route to polycyclic spiro-enones 2 from 2,2'-bis(allyloxy)-1,1'binaphthyls has been developed. The process presented herein involves an unprecedented RCM/Claisen sequence, which is promoted by commercially available Grubbs-type catalysts and readily takes place in a single catalytic event. Indisputably, the viability and scope of this new catalytic transformation render it a much more attractive and competitive method for the construction of these unusual polycyclic compounds, as compared to those described previously in the literature which lack generality, and are rather inefficient and poorly selective. ${ }^{14}$ This study thus reinforces that olefin metathesis catalysts can be remarkably effective in generating complex molecular architectures through new reaction pathways. Further studies aimed at broadening the scope of this catalytic process are currently in progress in our lab and will be the subject of future contributions.

Financial support from MICINN (CTQ2010-14796/BQU and CSD2007-00006) is acknowledged. J.F. and N.N. thank MEC of Spain and the ESF for the award of PhD grants.

\section{Notes and references}

1 See, for example: (a) Handbook of Metathesis, ed. R. H. Grubbs, Wiley-VCH, Weinheim, 2003; (b) A. H. Hoveyda and A. R. Zhugralin, Nature, 2007, 450, 243.

2 See, for example: (a) R. H. Grubbs, Tetrahedron, 2004, 60, 7117; (b) A. Deiters and S. F. Martin, Chem. Rev., 2004, 104, 2199; (c) S. K. Chattopadhyay, S. Karmakar, T. Biswas, K. C. Majumdar, H. Rahaman and B. Roy, Tetrahedron, 2007, 63, 3919; (d) S. Kotha and K. Lahiri, Synlett, 2007, 2767.

3 See, for example: (a) T. M. Trnka and R. H. Grubbs, Acc. Chem. Res., 2001, 34, 18; (b) C. Samojłowicz, M. Bieniek and K. Grela, Chem. Rev., 2009, 109, 3708; (c) S. P. Nolan and H. Clavier, Chem. Soc. Rev., 2010, 39, 3305.

4 (a) S. K. Collins, A. Grandbois, M. P. Vachon and J. Côté, Angew. Chem., Int. Ed., 2006, 45, 2923; (b) J. Côté and S. K. Collins, Synthesis, 2009, 1499.

5 (a) J. K. Bremmer, J. A. Coates, D. R. Coghlan, D. M. David, P. A. Keller and S. G. Pyne, New J. Chem., 2002, 26, 1549; (b) A. Garas, J. B. Bremmer, J. Coates, J. Deadman, P. A. Keller, S. G. Pynes and D. I. Rhodes, Bioorg. Med. Chem. Lett., 2009, 19, 3010.

6 (a) M. Arisawa, H. Kaneko, A. Nishida, K. Yamaguchi and M. Nakagawa, Synlett, 2000, 841; (b) M. Arisawa, H. Kaneko, A. Nishida and M. Nakagawa, J. Chem. Soc., Perkin Trans. 1, 2002, 959; (c) Y. A. Ibrahim and E. John, Tetrahedron, 2006, 62, 1001.

7 Competitive oligomerization of the substrates is commonly observed during RCM of diolefins: S. Monfette and D. E. Fogg, Chem. Rev., 2009, 109, 3783 and references cited therein.

8 (a) A. M. M. Castro, Chem. Rev., 2004, 104, 2939; (b) Claisen Rearrangement, ed. M. Hiersemann and U. Nubbemeyer, Wiley-VCH, Weinheim, 2007.

9 Structures related to A are rare: $(a)$ N. Kobayashi, Y. Kobayashi and T. Osa, J. Am. Chem. Soc., 1993, 115, 10994; (b) A. Saad, F. Barrière, E. Levillain, N. Vanthuyne, O. Jeannin and M. Fourmigué, Chem.-Eur. J., 2010, 16, 8020.

10 See, for example: (a) K. Plé, A. Haudrechy and N. P. Probst, Tetrahedron, 2010, 66, 5030; (b) N. P. Probst, A. Haudrechy and K. Plé, J. Org. Chem., 2008, 73, 4338; (c) S. Rotzoll, H. Görls and P. Langer, Synthesis, 2008, 45; (d) S. K. Chattopadhyay, S. P. Roy, D. Ghosh and G. Biswas, Tetrahedron Lett., 2006, 47, 6895; (e) S. Kotha, K. Mandal, A. Tiwari and S. M. Mobin, Chem.-Eur. J., 2006, 12, 8024; (f) V. Thornqvist, S. Manner, O. F. Wendt and T. Frejd, Tetrahedron, 2006, 62, 11793; $(g)$ P. Beaulieu and W. W. Ogilvie, Tetrahedron Lett., 2003, 44, 8883.

11 (a) B. Schmidt, Eur. J. Org. Chem., 2004, 1865; (b) B. Alcaide, P. Almendros and A. Luna, Chem. Rev., 2009, 109, 3817.

12 Note also that the observed dihedral angles between the two naphthalene ring systems in each binaphthyl unit of 3a $\left(74.59^{\circ}\right.$ and $88.03^{\circ}$ for one conformer, and $69.90^{\circ}$ and $82.20^{\circ}$ for the other one) are only slightly higher than that observed in the structure of its acyclic precursor $1 \mathrm{a}\left(69.05^{\circ}\right)$, which indicates that the steric strain within 3a is low: J.-C. Ge and H. Li, Acta Crystallogr., Sect. E: Struct. Rep. Online, 2009, 65, o1179.

13 Initial metathesis between $R$ and $S$ enantiomers of 1a explains the formation of the oligomers observed in the crude reaction mixtures since, in these cases, dimerization by a second RCM reaction results in a much less stable structure. In this sense, DFT calculations (B3LYP/6-31G(d)) showed that a hypothetical dimer showing a mixed $R S$ configuration of the binaphthyl units is $54.03 \mathrm{kcal} \mathrm{mol}^{-1}$ less stable than the $S S$ (or $R R$ ) one. Details are given in the ESI $\dagger$.

14 (a) Compound $\mathbf{B}$ was obtained by treatment of racemic $2,2^{\prime}$-dihydroxy-1,1'-binaphthyl with ethylene glycol ditosylate and $\mathrm{KOBu}^{\mathrm{t}}$ in refluxing THF: F. De Jong, M. E. Siegel and D. J. Cram, J. Chem. Soc., Chem. Commun., 1975, 551; (b) B is also formed by reacting $2,2^{\prime}$-dihydroxy-1,1'-binaphthyl with 1,2-dibromoethane in the presence of $\mathrm{K}_{2} \mathrm{CO}_{3}$ : A. R. Ramesha, K. Vishnumurthy, T. N. G. Row and S. Chandrasekaran, Indian J. Chem., Sect. B, 1999, 38, 1015; (c) Concerning compound C, it was generated by thermal treatment $\left(210^{\circ} \mathrm{C}\right)$ of 2-allyloxy-2'-hydroxy1,1'-binaphthyl under reduced pressure: Y. Nakamura, R. Hollenstein, J. Zsindely, H. Schmid and W. E. Oberhänsli, Helv. Chim. Acta, 1975, 58, 1949.

15 Evolution of 3a into 2a with longer reaction times was not observed, thus allowing us to discard its participation as a reaction intermediate.

16 In all the reactions depicted in Scheme 2 formation of minor amounts of macrocyclic dimers related to $\mathbf{3 a}$, as well as higher oligomers, was evidenced from the NMR spectra of the crude reaction mixtures. One of these dimers, i.e. $\mathbf{3 b}$, could be isolated in pure form (9\%) allowing its unambiguous characterization (see $\mathrm{ESI} \dagger$ ). 